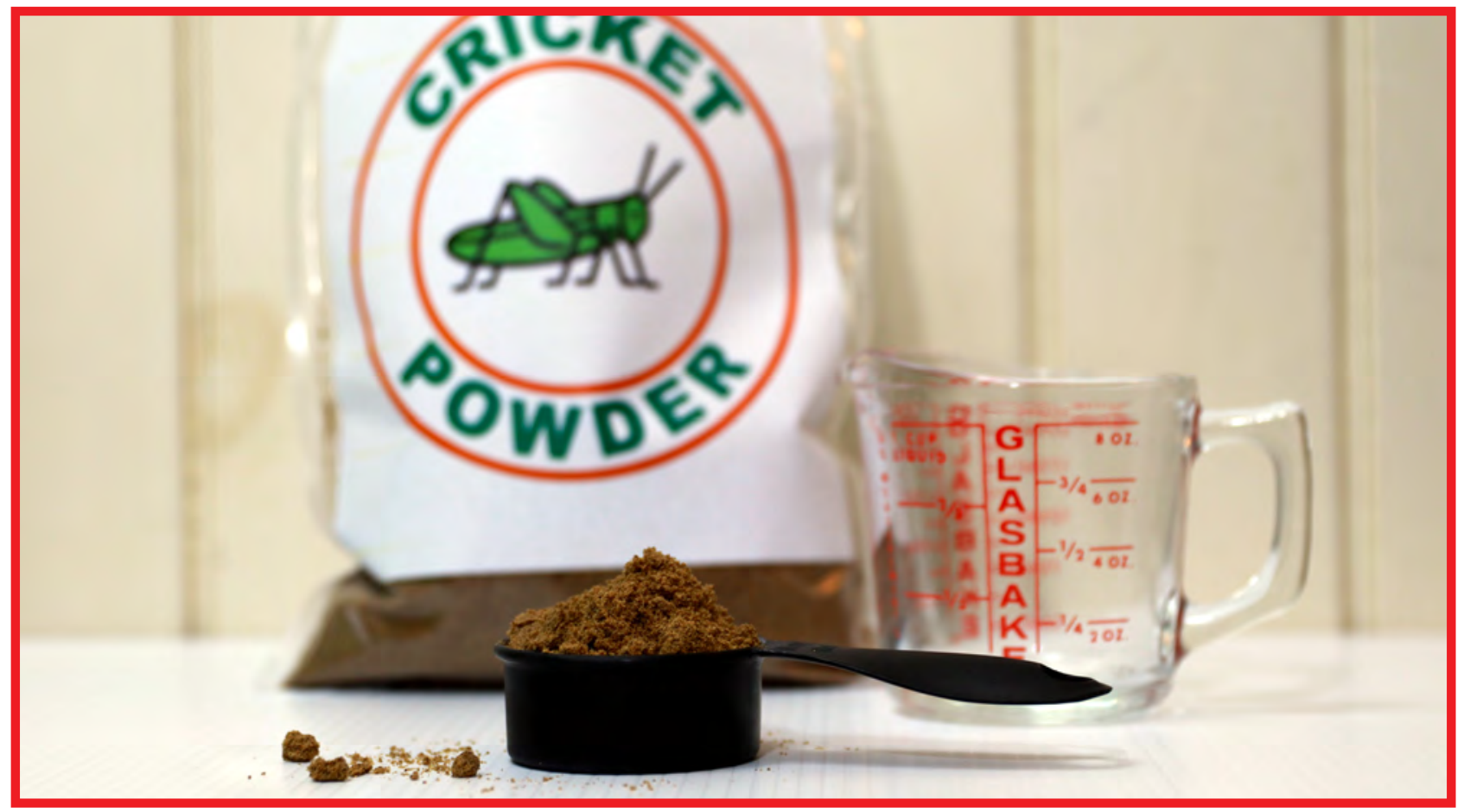

\title{
Variability in the Microbial Profile of Retail Cricket Powders in the U.S. Retail Market
}

\section{ABSTRACT}

Entomophagy has been touted as one of the solutions for present and likely upcoming food shortages, especially of protein-rich foods, due to the current pace of global population growth. "Minilivestock" require less water, space, and other resources compared to traditional livestock, which makes it an environmentally conscious option. Nonetheless, the Western world lags behind in the consumption of insects, and research and standardization of industrial practices are lacking. One of the most easily accessible insect-based foods in the United States is powdered cricket, which can be used as an adjunct to or substitute for traditional flours. We purchased two lots of eight brands of cricket powders and assessed their food quality and protein and fat composition. Counts of aerobic mesophiles, coliforms, Staphylococcus, fungi, Bacillus, presumptive Bacillus cereus, and aerobic and anaerobic spores varied greatly among brands as well as batches for the same brand. Protein and fat composition were similar on a $\mathrm{g} / 100 \mathrm{~g}$ basis among brands, but the labeled serving sizes varied from 10 to $36 \mathrm{~g}$, which made nutrition facts labels vary considerably. Standardization in multiple aspects, including demonstrated food safety, is paramount for the future of the industry.

\section{INTRODUCTION}

The preference of Western consumers for high-protein foods has been a sustained trend that has brought novel ingredients to consumer consciousness and to the marketplace. In the face of a rapidly changing climate, dietary sustainability has also become a more commonplace consideration, with "sustainability stories" playing a prominent role in ingredient and finished product marketing. One of the best examples of the convergence of these trends is the proliferation of products containing legume or pea protein, often called "plant protein." A virtually unknown ingredient in 2015 , legume protein is now a prominent ingredient in consumer products, including dairy-alternative beverages, breakfast cereals, and macaroni and cheese. Another ingredient existing at the nexus of sustainable and high-protein diets is insect meal. Whereas the consumption of insects is neither new nor 
novel in much of the world, Western countries, including the United States, lack a history of entomophagy. For this reason, the practice of eating insects has been, and often still is, perceived as unpleasant $(5,23)$ or unsafe $(23)$. Despite these culturally established biases, growing concerns around the detrimental environmental effects of raising livestock have driven the rapid appearance and continuing expansion of an insect protein industry and are expected to play a role in increasing acceptance of these novel foods (10). Worldwide, insects for human consumption primarily fall into the Coleoptera (beetle grubs), Lepidoptera (caterpillars), and Hymenoptera orders (wasps, bees, and ants) $(4,21)$. In the United States, however, the majority of commercially available products are composed of cricket (Acheta domesticus or Grylloides sigillatus from the order Orthoptera) ingredients.

\section{Ecological and production considerations}

The production of meat for human consumption is notoriously resource intensive. Recent estimates suggest that one-third of the cereal grains grown across the world are used as feed for livestock, and the already low feed conversion of meat animals (ranging from 2.3 for poultry to as high as 8.8 for beef) (22) is expected to decrease further in response to climate change (15). Conversely, "minilivestock" present several ecological advantages, including high feed conversion ratio (although this is extremely variable depending on species and diet composition) (12), higher edible weight percentage, and reduced space requirements $(21)$; they are also able to grow on a diet of waste products $(16,17)$, although this practice is not permitted in the European Union (21). From the standpoint of an entrepreneur, crickets may present several significant advantages, including the existence of small-scale apparatuses historically used to produce those insects as food for pets. The literature commonly extols the fact that crickets can be raised primarily, if not solely, on a diet of agricultural waste products $(16,17)$.

Moreover, many of the products that are currently available in retail outlets contain unfractionated (whole) ground crickets, representing a relatively minimal capital investment for processing equipment. In the European Union, insect products were named a "Novel Food," under Council Directive 2015/11/EC (1). In the United States, the consequences of this "novel" status are seen in several ways: first, the naming of products is highly variable, with cricket "powder," "flour," and "protein" used interchangeably. Further, there is no "reference amounts customarily consumed," which leaves producers to choose a serving size arbitrarily.

\section{Consumer and safety considerations}

Many studies have been conducted to assess consumer acceptance of insect-containing products and to determine whether consumers like or are willing to eat such products. In concept surveys, Swiss consumers reported significantly less disgust related to more-processed forms of insect (flour, pieces versus whole crickets) (5). In a blind test of cricketcontaining muffins, overall liking was statistically similar between control and treatment samples; panelists rated the texture of the cricket muffin as more enjoyable than that of the control, although the majority of participants indicated an unwillingness to consume crickets in an accompanying survey (2). Another study found that consumer willingness to pay for insect-containing foods was not only similar to their willingness to pay for control products but that it also increased when they understood the benefits associated with the test ingredient (10). Experimental exposure to insect-containing foods has been demonstrated to decrease aversion to future insect consumption. As exposure continues to grow, particularly through packaged goods, we expect to see some species of insects normalized as protein sources in the Western diet (8).

It has been well documented in the literature that crickets contain high levels of several microbiological indicator populations at the time of "harvest" $(9,11,19,20)$. Because harvest and processing methodologies are currently not standardized, little is known about the potential for products in the marketplace to exhibit high overall counts of microorganisms and to harbor foodborne pathogens. For this market to reach its potential, it is paramount that products available in the marketplace are consistently of high microbial, nutritional, and sensory quality and that they are safe to consume. In this study, we evaluate different brands of commercially available insect protein powders to assess the variability in microbial load within and across brands.

\section{MATERIALS AND METHODS}

Commercial products consisting of $100 \%$ powdered cricket ingredients $(n=8)$ were purchased online between fall 2018 and summer 2019. Each brand was purchased twice, at intervals of at least 3 months. Products were stored unopened at ambient temperature until analysis. Duplicate $10 \mathrm{~g}$ samples from each individual unit package were analyzed for microbial counts, with samplings on different days. Cricket powder was diluted $(1: 10)$ in sterile $0.1 \%$ peptone water (BD, Sparks, MD) and homogenized by hand for $2 \mathrm{~min}$. Subsequent serial dilutions were prepared as appropriate in $0.1 \%$ peptone water. Diluted samples were spread plated on acidified potato dextrose agar (Alpha Biosciences, Baltimore, MD), tryptic soy agar (Alpha Biosciences), Baird-Parker agar (Alpha Biosciences), and mannitol yolk polymyxin agar (HiMedia Laboratories LLC, Kennett Square, PA) and were incubated, respectively, for determination of fungi (ambient temperature for 5 days), aerobic mesophiles $\left(35 \pm 1^{\circ} \mathrm{C}\right.$ for $\left.48 \pm 2 \mathrm{~h}\right)$, Staphylococcus $\left(35 \pm 1^{\circ} \mathrm{C}\right.$ for $48 \pm 2 \mathrm{~h}$ ), and Bacillus $\left(30 \pm 1^{\circ} \mathrm{C}\right.$ for $24 \pm 2$ 
h) populations. The presence of colonies with morphology characteristic of Bacillus cereus was scored as absent (-), present $(+)$, or high $(++)$. The coliform population was determined using E. coli/Coliform Petrifilm (3M, St. Paul, $\mathrm{MN}$ ) according to manufacturer instructions. To determine the population of aerobic and anaerobic mesophilic spores, sample dilutions were heated at $80 \pm 2^{\circ} \mathrm{C}$ for $30 \mathrm{~min}$ and cooled at $50 \pm 2^{\circ} \mathrm{C}$ for $5 \mathrm{~min}$ before mixing with molten yeast dextrose agar (HiMedia Laboratories) and pour plating with and without thioglycolate agar (HiMedia Laboratories) overlay. Pour plates were prepared in quadruplicate with duplicate sets of plates incubated aerobically (no overlay) at $35 \pm 1^{\circ} \mathrm{C}$ for $48 \pm 2 \mathrm{~h}$ or anaerobically (with overlay) at $35 \pm 1^{\circ} \mathrm{C}$ for $48 \pm 2 \mathrm{~h}$ using the GasPak system (Thermo Scientific, Waltham, MA). All microbial populations were counted without visual aids and were logarithmically transformed for normality. Water activity was measured in duplicate using an Aqualab 4TE water activity meter (Meter Group, Pullman, WA). Moisture content was determined thermogravimetrically on a wet weight basis. Protein and fat values from package nutrition information were transformed to represent a $\mathrm{g} / 100 \mathrm{~g}$ measurement. Levels of fat and protein were determined experimentally using AOAC methods 35.1.23 and 993.13. Data were analyzed in IBM SPSS Statistics for Windows, version 25 (IBM Corp., Armonk, NY) using Pearson product-moment correlations and multivariate analysis of variance (ANOVA) (microbial data, brand, lot, and replicate as factors) or ANOVA (macronutrient data) with Tukey's honestly significant difference post hoc test. Some of the powdered cricket brands were not available for purchase for a third time. The authors recognize the limitations in the power of statistics of $n=2$ but believe that the results are still relevant to the food industry.

\section{RESULTS}

Despite the fact that all of the products analyzed in this study contained $100 \%$ ground cricket meal and no other ingredients, investigators observed several noteworthy differences in commercial packaging. Products were identified on the principal display panel alternately as cricket "powder," "protein powder," "flour," "protein," and "flour protein" (Table 1). Moreover, the suggested serving sizes ranged from 10 to $36 \mathrm{~g}$. Even though reported macronutrient content was highly similar on a g/100 g basis (excepting a single sample that was labeled as having been defatted), displayed values on the nutrition facts labels, particularly for protein, did not reflect this similarity because serving sizes were not standardized. Measured values for fat and protein content (data not shown) did not vary significantly from those expressed on product labels for any sample.

Water activity for all samples was minimal, with average values ranging from 0.154 to 0.314 . Notably, although two of the brands displaying higher water activity values (brands E and F at 0.294 and 0.291, respectively) also had

\section{TABLE 1. Label features, moisture, and water activity of commercial cricket powders ${ }^{a}$}

\begin{tabular}{|c|c|c|c|c|c|c|c|c|}
\hline Brand & Designation & $\begin{array}{l}\text { Serving size } \\
(\mathrm{g})\end{array}$ & $\begin{array}{l}\text { Protein } \\
\text { g/serving }\end{array}$ & $\mathrm{g} / 100 \mathrm{~g}$ & $\begin{array}{c}\text { Fat } \\
\mathrm{g} / \text { serving }\end{array}$ & $\mathrm{g} / 100 \mathrm{~g}$ & $\begin{array}{l}\text { Moisture } \\
(\% \text { wwb) }\end{array}$ & Water activity \\
\hline A & Powder & 12 & 8 & 67 & 3 & 25 & $2.30 \pm 0.02$ & $0.189 \pm 0.001$ \\
\hline $\mathrm{B}$ & Protein powder & 20 & 13 & 65 & 4 & 20 & $2.25 \pm 0.2$ & $0.154 \pm 0.002$ \\
\hline $\mathrm{C}$ & $\begin{array}{c}\text { Flour } \\
(100 \% \text { defatted })\end{array}$ & 10 & 8 & 80 & 0.5 & 5 & $2.01 \pm 0.35$ & $0.201 \pm 0.001$ \\
\hline $\mathrm{D}$ & Powder & 17 & 11 & 65 & 3 & 18 & $1.95 \pm 0.74$ & $0.170 \pm 0.001$ \\
\hline $\mathrm{E}$ & Powder & 31 & 20 & 65 & 7 & 23 & $3.52 \pm 0.29$ & $0.294 \pm 0.003$ \\
\hline $\mathrm{F}$ & Protein & 25 & 17 & 68 & 5 & 20 & $3.72 \pm 0.24$ & $0.291 \pm 0.002$ \\
\hline G & Flour protein & 36 & 25 & 69 & 5 & 14 & $2.07 \pm 0.15$ & $0.195 \pm 0.001$ \\
\hline $\mathrm{H}$ & $\begin{array}{l}\text { Protein } \\
\text { (organic) }\end{array}$ & 18 & 12 & 67 & 4 & 22 & $4.64 \pm 0.06$ & $0.314 \pm 0.004$ \\
\hline Avg & $\mathrm{N} / \mathrm{A}$ & $21 \pm 9$ & $14 \pm 6$ & $66 \pm 2^{b}$ & $4 \pm 2$ & $20 \pm 4^{b}$ & $2.81 \pm 1.01$ & $0.226 \pm 0.063$ \\
\hline
\end{tabular}

${ }^{a}$ wwb, wet weight basis. $n=2$ per brand. Moisture and water activity values represented as mean \pm SD.

${ }^{b}$ Average computed without the inclusion of brand $\mathrm{C}$ due to fat removal. 


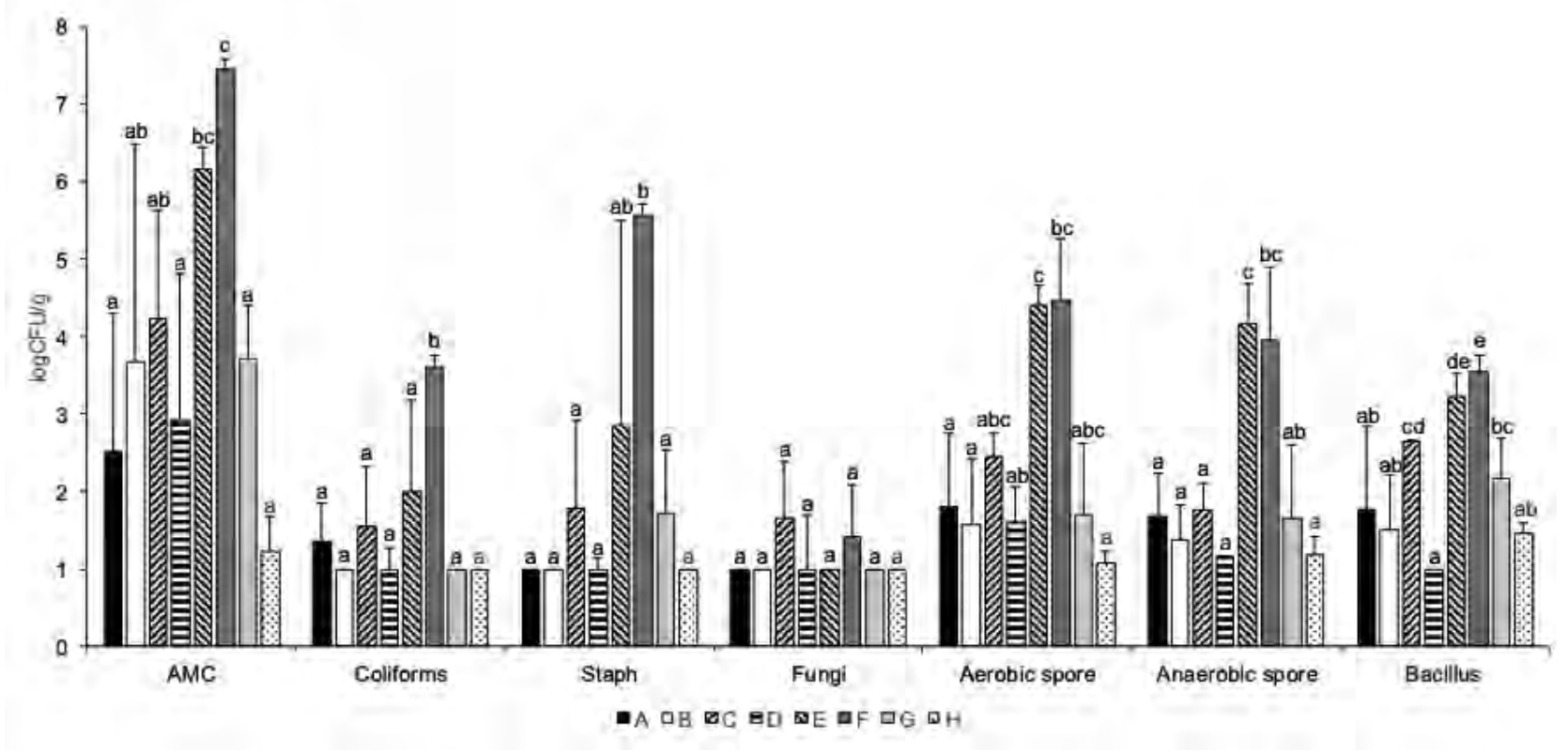

FIGURE 1. Microbial load in different cricket flour brands (A to $\mathrm{H}$ ) expressed in log CFU/g. Different letters show significant statistical differences $(P<0.05)$ among brands for individual microbial analysis using multivariate ANOVA with Tukey's honestly significant difference post hoc test. AMC, aerobic mesophile counts; Staph, Staphylococcus. Error bars express standard deviation.

the highest counts for most enumerated populations, brand $\mathrm{H}$, which had the highest average water activity (0.314), had significantly lower counts for every population when compared to brands $\mathrm{E}$ and $\mathrm{F}$.

Both producer and lot exerted significant effects on counts at the model level (Fig. 1). Aerobic mesophile count values varied from $<1$ to $7.6 \mathrm{log} \mathrm{CFU} / \mathrm{g}$ and were strongly correlated with high coliform, Staphylococcus, Bacillus, and spore counts as well as presence of presumptive B. cereus. Levels of fungi were largely below the detection limit (10 $\mathrm{CFU} / \mathrm{g})$, and E. coli was not detected in any sample $(<10$ $\mathrm{CFU} / \mathrm{g}$ ).

Levels of aerobic and anaerobic mesophilic spores, as well as Bacillus, were similar within brands, suggesting that Bacillus spp. comprise the majority of the spores present in the product. Higher Bacillus counts on mannitol yolk polymyxin agar were associated with a greater likelihood of the presence of presumptive B. cereus (Table 2).

\section{DISCUSSION}

Projected growth in the global population is expected to drive significant increases in demand for high-quality protein in the coming years. Insect-based foods are relatively new to the Western marketplace, and, therefore, detailed information regarding standard practices in production and processing, particularly for large-scale operations, is lacking. For these products to grow in consumption, particularly among Western consumers, it will be necessary to build trust in such products as a way to circumvent ingrained, negative perceptions related to entomophagy. As displayed in (Table 1), current labeling on cricket products may inadvertently mislead consumers regarding differences among brands due to the lack of standardization of serving size.

Additionally, although experimentally determined protein concentrations were similar to those displayed on nutrition facts labels, experimental data were not adjusted to account for chitin, which represents a significant amount of the nitrogen content of insects' exoskeletons. Humans' ability to digest chitin is still not fully understood, with mixed results in the literature $(7,14)$. It would be reasonable to assume, therefore, that protein values may be overstated.

The cost in consumer confidence resulting from an outbreak or recall situation at this stage in the growth of the edible insect market could be expected to hinder industry growth significantly. Whereas prior studies have suggested that much of the microbiota of insect food products originates in the feed used during rearing (20), it has also been demonstrated that significant changes in microbiota occur as the result of processing (11). The production of ground protein products, such as those assessed in this study, most commonly relies on oven drying, often in combination with some application of heat, whether blanching or roasting. A 2017 study assessing the microbiota of processed A. domesticus, as well as a 


\section{TABLE 2. Presumptive load of BC and Bacillus count in commercial cricket powdersa}

\begin{tabular}{c|c|c|c}
\multirow{2}{*}{ Brand } & \multicolumn{2}{|c}{ Presumptive BC } & Bacillus count \\
Avg & Sample 2 \\
\cline { 2 - 4 } & Sample 1 & + & 1.76 \\
\hline A & - & + & 1.50 \\
\hline B & - & + & 2.64 \\
\hline C & + & + & 1.00 \\
\hline D & - & ++ & 3.23 \\
\hline E & ++ & + & 3.54 \\
\hline F & ++ & + & 2.17 \\
\hline H & + & + & 1.46 \\
\hline
\end{tabular}

${ }^{a} \mathrm{BC}$, Bacillus cereus. Bacillus count given as log CFU/g. -, absent; +, present (up to 2 CFU per plate); ++, high (3 or more CFU per plate).

2018 study that analyzed commercial Gryllodes sigillatus, revealed levels of Bacillus spp. similar to those documented in this work $(13,20)$. The earlier study also conclusively identified the presence of $B$. cereus in commercial cricket powder produced in Europe. G. sigillatus contained lower levels of Enterobacteriaceae, despite higher water activity. Most notably, processing (including drying and smoking) was associated with significant increases in both total viable count and spores (20). However, the extent to which processing practices may affect the microbial quality of the finished product is difficult to ascertain due in part to the significant differences in multiple counts observed across lots of product from the same manufacturer, as well as the inherent variables that can affect the microbial load in any food processing environment. This phenomenon was also observed in an analysis of unprocessed, commercially reared insects (including $A$. domesticus) conducted in Belgium, with authors noting that physicochemical properties were insufficient to explain large differences in microbial populations within brands across batches (19).

Even though cricket products overwhelmingly dominate insect products currently available to U.S. consumers, crickets are not among the most commonly consumed insects worldwide (21). It is estimated that approximately 2,000 species of insects are currently consumed in various parts of the world, with the greatest proportions being composed of beetles and Lepidoptera (e.g., grubs and caterpillars) (21). Microbiological quality has been reported to vary significantly among species of insects (6). Assessments of the relative microbial risks associated with protein from other species of insects would be wise at this early stage of the industry. For example, the transmission of intestinal flukes from the consumption of dragonflies has been documented (3).
Additionally, risks of nonmicrobial origin, including bioaccumulation of heavy metals and allergenicity, should be specifically assessed. These hazards, in particular, may be associated with the life-cycle stage of the insect at the time of harvest, a factor that has not been addressed directly in the published literature. Cross-reactivity of proteins from highly allergenic foods such as shrimp with various species of insect have been documented in a number of studies and is believed to be due in large part to the pan-allergenicity of invertebrate tropomyosin, as reviewed in van der Fels-Klerx et al. (18).

Having a more comprehensive understanding of the hazards associated with entomophagy and standardizing labeling and processing techniques is paramount for the establishment of the insect protein industry as a viable player in today's well-informed and environmentally conscious market.

\section{ACKNOWLEDGMENTS}

We thank Kathy Davis-Dentici for her incomparable working ethic and laboratory efficiency. This project was supported by the U.S. Department of Agriculture, National Institute of Food and Agriculture, Hatch Project number ME0-21915, through the Maine Agricultural and Forest Experiment Station. Maine Agricultural and Forest Experiment Station Publication number 3735. 


\section{REFERENCES}

1. Anonymous. 2015. Council directive 2015/11/EC on on novel foods. Off. J. Eur. Union L. 327:1-22.

2. Burt, K. G., T. Kotao, I. Lopez, J. Koeppel, A. Goldstein, L. Samuel, and M. Stopler. 2019. Acceptance of using cricket flour as a low carbohydrate, high protein, sustainable substitute for all-purpose flour in muffins. J. Culin. Sci. Technol. 18:201-213.

3. Chai, J. Y., E. H. Shin, S. H. Lee, and H. J. Rim. 2009. Foodborne intestinal flukes in Southeast Asia. Korean J. Parasitol. 47:S69S102.

4. Gahukar, R. T. 2011. Entomophagy and human food security. Int. J. Trop. Insect Sci. 31:129-144.

5. Gmuer, A., J. Nuessli Guth, C. Hartmann, and M. Siegrist. 2016. Effects of the degree of processing of insect ingredients in snacks on expected emotional experiences and willingness to eat. Food Qual. Prefer. 54:117-127.

6. Grabowski, N. T., and G. Klein. 2017. Microbiology of cooked and dried edible Mediterranean field crickets (Gryllus bimaculatus) and superworms (Zophobas atratus) submitted to four different heating treatments. Food Sci. Technol. Int. 23:17-23.

7. Janiak, M. C. 2018. No evidence of copy number variation in acidic mammalian chitinase genes (CHIA) in New World and Old World monkeys. Int. J. Primatol. 39:269-284.

8. Jensen, N. H., and A. Lieberoth. 2019. We will eat disgusting foods togetherevidence of the normative basis of Western entomophagy-disgust from an insect tasting. Food Qual. Prefer. 72:109-115.

9. Klunder, H. C., J. Wolkers-Rooijackers, J. M. Korpela, and M. J. R. Nout. 2012. Microbiological aspects of processing and storage of edible insects. Food Control 26:628-631.
10. Lombardi, A., R. Vecchio, M. Borrello, F. Caracciolo, and L. Cembalo. 2019. Willingness to pay for insect-based food: the role of information and carrier. Food Qual. Prefer. 72:177-187.

11. Milanović, V., F. Cardinali, L. Aquilanti, C. Garofalo, A. Roncolini, R. Sabbatini, F. Clementi, and A. Osimani. 2019. A glimpse into the microbiota of marketed ready-toeat crickets (Acheta domesticus). Indian J. Microbiol. 60:115-118.

12. Oonincx, D. G. A. B., S. Van Broekhoven, A Van Huis, and J. J. A. Van Loon. 2015. Feed conversion, survival and development, and composition of four insect species on diets composed of food by-products. PLoS One 14(10):e0222043.

13. Osimani, A., C. Garofalo, V. Milanović, M. Taccari, F. Cardinali, L. Aquilanti, M. Pasquini, M. Mozzon, N. Raffaelli, S. Ruschioni, P. Riolo, N. Isidoro, and F. Clementi. 2017. Insight into the proximate composition and microbial diversity of edible insects marketed in the European Union. Eur. Food Res. Technol. 243:1157-1171.

14. Paoletti, M., L. Norberto, R. Damini, and S. Musumeci. 2007. Human gastric juice contains chitinase that can degrade chitin. Ann. Nutr. Metab. 51:244-251.

15. Rojas-Downing, M. M., A. P. Nejadhashemi, T. Harrigan, and S. A. Woznicki. 2017. Climate risk management climate change and livestock: impacts, adaptation, and mitigation. Clim. Risk Manag. 16:145-163.

16. Smetana, S., M. Palanisamy, A. Mathys, and V. Heinz. 2016. Sustainability of insect use for feed and food: life cycle assessment perspective. J. Clean. Prod. 137:741-751.

17. Surendra, K. C., R. Olivier, J. K. Tomberlin, R. Jha, and S. K. Khanal. 2016. Bioconversion of organic wastes into biodiesel and animal feed via insect farming. Renew. Energy 98:197-202.
18. van der Fels-Klerx, H. J., L. Camenzuli, S. Belluco, N. Meijer, and A. Ricci. 2018. Food safety issues related to uses of insects for feeds and foods. Compr. Rev. Food Sci. Food Saf. 17:1172-1183.

19. Vandeweyer, D., S. Crauwels, B. Lievens, and L. Van Campenhout. 2017. Microbial counts of mealworm larvae (Tenebrio molitor) and crickets (Acheta domesticus and Gryllodes sigillatus) from different rearing companies and different production batches. Int. J. Food Microbiol. 242:13-18.

20. Vandeweyer, D., E. Wynants, S. Crauwels, C. Verreth, N. Viaene, J. Claes, B. Lievens, and L. Van Campenhout. 2018. Microbial dynamics during industrial rearing, processing, and storage of tropical house crickets (Gryllodes sigillatus) for human consumption. Appl. Environ. Microbiol. 84(12):pi=e00255-18.

21. van Huis, A., J. Van Itterbeeck, H. Klunder, E. Mertens, A. Halloran, G. Muir, and P. Vantomme. 2013. Edible insects: future prospects for food and feed security. Food and Agriculture Organization of the United Nations (FAO), Rome.

22. Wilkinson, J. M. 2011. Re-defining efficiency of feed use by livestock. Animal 5:1014-1022.

23. Woolf, E., Y. Zhu, K. Emory, J. Zhao, and C. Liu. 2019. Willingness to consume insectcontaining foods: a survey in the United States. LWT - Food Sci. Technol. 102:100-105. 